\title{
Formation of Vertebral Precursors: Past Models and Future Predictions
}

\author{
RUTH E. BAKER ${ }^{\mathrm{a}, *}$, SANTIAGO SCHNELL ${ }^{\mathrm{b}, \dagger}$ and PHILIP K. MAINI ${ }^{\mathrm{a}, \mathrm{t}}$ \\ ${ }^{\mathrm{a}}$ Centre for Mathematical Biology, Mathematical Institute, 24-29 St Giles, Oxford OX1 3LB, UK; ${ }^{\mathrm{b}}$ Christ Church, Oxford, OX1 1DP, UK
}

(Received and accepted 18 July 2003)

\begin{abstract}
Disruption of normal vertebral development results from abnormal formation and segmentation of the vertebral precursors, called somites. Somitogenesis, the sequential formation of a periodic pattern along the antero-posterior axis of vertebrate embryos, is one of the most obvious examples of the segmental patterning processes that take place during embryogenesis and also one of the major unresolved events in developmental biology. We review the most popular models of somite formation: Cooke and Zeeman's clock and wavefront model, Meinhardt's reaction-diffusion model and the cell cycle model of Stern and co-workers, and discuss the consistency of each in the light of recent experimental findings concerning FGF-8 signalling in the presomitic mesoderm (PSM). We present an extension of the cell cycle model to take account of this new experimental evidence, which shows the existence of a determination front whose position in the PSM is controlled by FGF-8 signalling, and which controls the ability of cells to become competent to segment. We conclude that it is, at this stage, perhaps erroneous to favour one of these models over the others.
\end{abstract}

Keywords: Vertebral precursors; Somitogenesis; Congenital vertebral defects; Theoretical models; Segmentation clock; FGF-8 signalling

\section{INTRODUCTION}

Somitogenesis is a complex process that results in the segmentation of a seemingly uniform field of cells along the antero-posterior (AP) axis of vertebrate embryos, known as the presomitic mesoderm (PSM), into repeated blocks of cells: the somites. Somite formation is one of the most obvious examples of the patterning processes that take place during embryogenesis and is perhaps a leading candidate in developmental biology for a study that aims to couple the recent findings at the molecular level with the classical observations at the cell and tissue level. As such, somitogenesis may be thought of as serving as an important paradigm model for investigating multi-scale effects in general. In fact, somitogenesis is a process tightly regulated both in time and space, which poses a challenge to cellular and molecular biologists and also to mathematical biologists. Some of the processes involved include the role of biological clocks, gene expression, cell differentiation and cell-cell signalling (Schnell et al., 2000; 2002).
In the mesoderm of the chick, events leading to the formation of somites begin when the notochord is laid down as Hensen's node regresses along the AP axis with the primitive streak. After the notochord is laid down, mesodermal cells migrate laterally to form thick bands of cells which run longitudinally along each side of the embryo. Soon after the PSM forms, the process of somitogenesis begins; cells in the PSM undergo changes in their adhesive and migratory properties and condense together to form epithelial blocks of cells known as somites. The somites bud off from the PSM at regular intervals, the first forming at the anteriormost end and with subsequent somites forming in a strict AP sequence (Gossler and Hrabě de Angelis, 1998; Stickney and Devoto, 2000; Stockdale et al., 2000). This budding of somites from the PSM compensates for the addition of cells via cell division and from the node, and keeps the PSM approximately constant in length, so that a wave appears to move down the AP axis leaving somites in its wake. The pattern is in fact static in the trunk of the chick, with

\footnotetext{
*E-mail: bakerr1@maths.ox.ac.uk

Corresponding author. Tel.: +44-01865-286855. Fax: +44-01865-270515. E-mail: schnell@maths.ox.ac.uk

E-mail: maini@maths.ox.ac.uk
} 
cells moving up through it as they develop (Collier et al., 2000; Schnell et al., 2002).

Somites are divided by a fissure into anterior and posterior halves and they are approximately regular in size, occur in pairs and lie on either side of the notochord, which eventually will become the spinal cord. Vertebrae are formed by the fusion of the posterior half of a rostral somite with the anterior half of the neighbouring caudal somite. Somite formation shows capacity for global regulation, the ability to achieve constant proportions despite wide variation among individuals in the amount of tissue available whilst the pattern is forming: the variability of somite number within a species is $<5 \%$ (Cooke, 1975).

A number of genetic or environmental factors can disturb somitogenesis and affect somite size. If somitogenesis is disrupted slightly, congenital vertebral defects are produced. In fact, there are many recognised clinical conditions that can occur as a result, such as Klippel-Feil syndrome, spondylocostal dysostosis, Jarcho-Levin syndrome, congenital scoliosis, kyphosis and Goldenhar syndrome (Pourquié and Kusumi, 2001). Congenital vertebral anomalies can result from transient hypoxia (Ingalls and Cureley, 1957; Murakami and Kameyama, 1963; Rivard, 1986) or exposure to toxic elements (Murray et al., 1979; Schwetz et al., 1979; Singh et al., 1993; Loder et al., 2000) during the fatal period. The nature and extent of the malformations induced depend on the stage of somitogenesis (Rivard et al., 1979), and include many gross vertebral and associated skeletal defects such as vertebral fusion, failure of vertebral formation, fragmented vertebral bodies, bifid ribs, junctions of two or more ribs (Pourquié and Kusumi, 2001; Erol et al., 2002). Studies in animal models have shown that many genes regulate somite formation, particularly that genes of the Notch/Delta pathway are necessary for normal somite formation in the mouse (Evrard et al., 1998; Zhang and Gridley, 1998; del Barco Barrantes et al., 1999; Jiang et al., 2000). Mutation in some human Notch genes have been associated with vertebral defects (Li et al., 1997; Oda et al., 1997; Bulman et al., 2000). Studying the developmental mechanisms in vertebral patterning will aid in the identification of protective or potentially disruptive factors for normal somitogenesis, and could lead towards treatments for the prevention of vertebral patterning disorders.

One environmental factor reported to disturb somitogenesis in animal models is heat shock. Heat shocks applied to chick embryos can induce the formation of an extra somite or can result in up to four repeated anomalies, suggesting that heat shock affects an oscillatory process within somite formation (see Veini and Bellairs, 1986, for a review). In 1976, from this heat shock observation, Cooke and Zeeman (1976) presented a model for somitogenesis called the "Clock and Wavefront Model" which proposes that somite formation depends on two parameters. The first is a cellular oscillator that gives temporal information to the PSM cells. The second is a wavefront, say a sudden change in cell behaviour, which continuously crosses the embryo in the AP direction, providing spatial information for somite boundary formation.

Several years later, single heat shock experiments in chick embryos (Primmett et al., 1988) revealed that a number of somitic anomalies separated by relatively constant distances of six to seven normal somites can occur. The repeated anomalies suggest that heat shock affects an oscillatory process of the cell cycle within the somite precursor cells (Primmett et al., 1988; 1989; Stern et al., 1988) since six to seven somites corresponds to one cell cycle worth of PSM cells and heat shock blocks cells at a certain stage of their cell cycle. Similar periodic anomalies in somite formation can also be caused by drugs inhibiting cell cycle progression (Primmett et al., 1989). There is some degree of cell cycle synchrony between the cells in the PSM which are destined to segment together to form a somite (Stern and Bellairs, 1984). From these experimental observations, Stern et al. (1988) developed an alternative model for somitogenesis called the "Cell Cycle Model" (see also Primmett et al., 1989). This model relies on the existence of a relative synchrony among PSM cells with respect to their cell cycle. It postulates the existence of a defined time interval within the cell cycle that corresponds to the formation time of a somite. During this time interval, cells become able to respond to a given signal such that all cells that are between $P_{1}$ and $P_{2}$ become allocated to the same somite. One important point is that the cell cycle is the only component driving both the spatial and temporal organisation of the somites.

In 1997, Palmeirim et al. (1997) described a pulsing expression of genes whose periodicity corresponds to the formation time of one somite. Perturbation of several of these genes expressed in the PSM has also been shown to affect somite formation. Mutations for Notch1, RBPJK, $D l l 1, l$-fng have somites with irregular size and shape and the anterior-posterior polarity of somites is also affected (del Barco Barrantes et al., 1999). During the time taken for one somite to form, expression of c-hairy-l and l-fng appears to sweep along the PSM in the posterior-anterior direction, narrowing as it moves along, until it comes to rest in the posterior half of the forming somite (Palmeirim et al., 1997; McGrew et al., 1998). This wavefront-like expression activates several genes of the Notch/Delta pathway (del Barco Barrantes et al., 1999; Jiang et al., 2000; Schnell and Maini, 2000) and is considered to be the result of a "segmentation clock" acting within the PSM cells, as predicted by the Cooke and Zeeman (1976) model. Another model in agreement with these gene oscillations is the "Reaction-Diffusion Model" proposed by Meinhardt $(1982,1986)$. In this model, cells have two states — "anterior" and "posterior" — which locally exclude each other, but stimulate each other over a long range. Cells switch from one state to the other until finally reaching a stable state. This can lead to a pattern of stable ... anterior-posterior-anterior-posterior ... units forming along the AP axis. Unlike the other models, 
the segment size is defined by the intrinsic parameters of the oscillator. However, it is not yet known whether the major role of $c$-hairy- 1 and $l$-fng is in the allocation of cells to individual somites or rather in the subdivision of somites into anterior and posterior compartments (Collier et al., 2000).

More recently, Dubrulle et al. (2001) and Sawada et al. (2001) have used experimental findings to suggest that in fact it is an interaction between FGF-8 signalling and the segmentation clock that controls somite size. They have reported that the wavefront-like expression of genes observed by Palmeirim et al. (1997) in the PSM could be assimilated into a travelling wave threshold of FGF-8 responsible for positioning somitic boundaries. The experimental results of Dubrulle et al. (2001) and Sawada et al. (2001) show that the PSM is not a homogeneous tissue, but consists of two distinct parts which differ with respect to their gene expression and also their degree of segmental determination: the anterior region in which the epithelialization process has begun, cells have become committed to form part of a somite and are fixed with respect to their AP polarity, and the posterior region in which the cells are not committed or are immature. These two regions are divided by their level of FGF-8 signalling; low in the anterior region where segmentation has begun and high in the posterior region where it has not. The border which separates the two regions of the PSM is known as the determination front. Dubrulle et al. (2001) find that FGF-8 is sufficient to maintain the caudal identity of PSM cells and they suggest that down-regulation of FGF signalling in the PSM at the level of the determination front is required for cells to proceed further with the segmentation process.

Local application or inhibition of FGF-8 by implantation of a bead soaked in FGF-8 in or next to the PSM, or injection with certain drugs, are environmental factors that also affect somitogenesis. The result of any of these perturbations is the formation of a sequence of up to 6-7 abnormally sized somites (Dubrulle et al., 2001; Sawada et al., 2001). It is hypothesised that this is a direct result of the displacement of the determination front from its constant axial position by a change in FGF-8 signalling.

In this article, we present a critical review of three of the more widely used contender models for somitogenesis: (i) Cooke and Zeeman's clock and wavefront model, (ii) Meinhardt's reaction-diffusion model and (iii) Stern and co-workers cell cycle model. Our paper aims to show that, in the light of recent data, none of these models is capable of fully explaining FGF-8 signalling in the PSM. We show that some aspects of the cell cycle model, which previous authors have overlooked, link nicely with the experimental data. We explain how the cell cycle model can be extended to take into account the effects of FGF-8 and that it can predict the experimental results of Dubrulle et al. (2001) and Sawada et al. (2001). We also present an algorithm which can be applied to the cell cycle model to predict the effects of local application of FGF-8 in terms of the rate at which PSM cells mature to become competent to segment and form somites. This is followed by a conclusion.

\section{THEORETICAL MODELS FOR SOMITOGENESIS}

Over the past three decades there have been a number of models proposed to account for somite formation. By definition, a model is a partial representation of reality and therefore cannot account for all experimental observations. The role of modelling is to provide insight as to how complex biological processes may be coupled to produce experimentally observed behaviour. Schnell and Maini (2000) and Schnell et al. (2000) critically reviewed several models for somitogenesis. Below, we briefly consider three of the more widely used models to explain somite formation in the light of recent experimental findings concerning FGF-8 signalling in the PSM.

\section{The Clock and Wavefront Model}

Zeeman (1974) and Cooke and Zeeman (1976) propose a clock and wavefront model to explain somite formation. They postulate the existence of a longitudinal "positional information" gradient down the AP axis of the embryo which determines regional development by setting the time in each cell at which it will undergo a "catastrophe". By "catastrophe", they mean a rapid change of state, which could possibly be the rapid change in locomotory and adhesive behaviour of cells when they form somites. The "clock" is a smooth cellular oscillator, which interacts with the wavefront, periodically inhibiting or altering its passage down the axis. The integration of the clock and the wavefront would gate the PSM cells into groups to segment together, producing a periodic pattern of somites.

Discovery of the periodic expression of c-hairy- 1 and several other genes related to the Notch signalling pathway provides molecular evidence for the existence of a clock in the PSM (Palmeirim et al., 1997). Dubrulle et al. (2001) propose that the transit of cells from the posterior (FGF-8 expressing) part of the PSM to the anterior (non-expressing) part of the PSM is able to constitute the wavefront of Cooke and Zeeman's model. Since the discovery of the cycling genes in the PSM, the clock and wavefront model has generally been favoured for explaining somitogenesis and with Dubrulle and co-workers' discovery of the FGF-8 defined determination front, many authors have proposed extensions to the clock and wavefront model for somite formation (Pourquié and Kusumi, 2001; Saga and Takeda, 2001; Dubrulle et al., 2001).

In the clock and wavefront model, somite size is a function of the frequency of the segmentation clock and also of the velocity of the maturation wavefront. An increase in the size of somites could be caused by either a slowing down of the oscillation of the clock, while the speed of the wavefront is kept constant, or by accelerating the progression of the wavefront, while 
keeping the period of the clock oscillations constant. The former is not a feasible explanation for the observed change in somite size on application of FGF-8 since implantation of an FGF-8 soaked bead into the PSM causes no asynchrony in the timing of somite boundary formation and the period of the cycling genes is not affected by the bead graft (Dubrulle et al., 2001). The latter seems to be a possible explanation that is consistent with experimental evidence; advancing the wavefront through inhibition of FGF-8 signalling would cause the determination front to be displaced more caudally, and hence result in the formation of a larger somite. The reverse would apply for the formation of an abnormally small somite.

The model, however, seems to be inconsistent with the discovery of FGF-8 signalling patterns: although it may be able to explain the production of abnormally large and small somites, it cannot explain the effects of local application of FGF-8. According to Vasiliauskas and Stern (2001), the clock and wavefront model predicts that a cranial shift of the wavefront would first generate small somites, then a series of normal somites, followed by a larger somite at a position where the wavefront reverted to normal. This prediction seems to be contradicted by the results of Dubrulle et al. (2001) showing the formation of several small somites ahead of the bead, followed by a larger somite behind the bead and then normal somites. However, this inconsistency requires further investigation, because the FGF-8 bead remains in place during the formation of several somites in the experiments of Dubrulle et al. (2001), and the predictions of Vasiliauskas and Stern (2001) would probably be valid if the release of FGF-8 is limited to the formation of one somite.

The cyclic and wavefront-like expression of c-hairy-1 and $l$-fng is considered to be the result of a "segmentation clock" acting within the PSM cells, as predicted by the Cooke and Zeeman (1976) model. However, it is important to emphasise that the model is unable to explain that the maximum distances over which anomalies can extend is a region equivalent to 6-7 somites, which, as mentioned previously, corresponds to one cell cycle worth of PSM cells. In the light of new experimental evidence on the cycling times of c-hairy- 1 and $l$-fng in the PSM (Palmeirim et al., 1997), these genes have been linked to the segmentation clock (Cooke, 1998) and away from the cell cycle itself.

\section{Reaction-Diffusion Model}

Meinhardt (1986) proposed a reaction-diffusion model to account for somite formation. He assumed that cells can be in one of two possible states, denoted by $\mathbf{a}$ and $\mathbf{p}$, respectively. If a cell is in state $\mathbf{a}$, then the genes that are responsible for synthesis of a substance $\mathrm{X}$ are turned on and similarly for a cell in state $\mathbf{p}$ and a corresponding substance Y. The states a and $\mathbf{p}$ are such that they locally exclude each other, but stimulate each other over a long range. Cells will switch from one state to another until they reach a stable state. In this way a pattern of stable apap... stripes is formed in the AP direction. The transition from $\mathrm{X}$ expressing cells to $\mathrm{Y}$ expressing cells, say, would constitute a change of segmental specification: it may be that the anterior and posterior halves of the somites could be represented by the expression of $\mathrm{X}$ and $\mathrm{Y}$. Each ap pair or segment would be specified more posteriorly than its predecessor, resulting in the specification of somites with different regional characteristics.

Meinhardt (1986) proposed two possible mechanisms that could control the switch between states: (i) Presence of a morphogen gradient, in which a threshold level of the substance $\mathrm{X}$ would be required for a cell to switch to state a. (ii) Domain outgrowth. New segments would be added as the domain grows in a posterior direction.

Evidence supporting Meinhardt's model comes from the expression of c-hairy-1 in the PSM (Dale and Pourquie, 2000). As a newly formed somite buds off from the PSM, its anterior half is devoid of c-hairy-1 expression, whilst the posterior half continues to maintain c-hairy-1 expression. Cells oscillate between anterior (c-hairy-1 off) and posterior (c-hairy-1 on) states, which become stabilised in the anterior part of the PSM (Dale and Pourquie, 2000). Meinhardt's model is currently the only one that addresses anterior/posterior somite subdivision. We should also note that the FGF-8 gradient shown to be present in the PSM could constitute the positional information gradient required by the cells in order for the pattern to start forming.

However, in its present form, the reaction-diffusion model cannot explain the effects of local FGF-8 application and without a link to the cell cycle, it will not be able to predict that the maximum distances over which FGF-8 somite anomalies can occur is equivalent to one cell cycle.

\section{The Cell Cycle Model}

The cell cycle model of Stern and co-workers (Primmett et al., 1988; Stern et al., 1988; Primmett et al., 1989) links the cell cycle with somite segmentation. The main observations on which the hypotheses of this model are based include the following: (i) The time interval between specification of successive presumptive somites is approximately $90-100 \mathrm{~min}$, equivalent to approximately one seventh of the cell cycle $(9-10 \mathrm{~h})$. (ii) There exist discrete regions of cell synchrony in the PSM. (iii) Application of a single transient heat shock to chick embryos blocks the cell cycle. This causes several somitic anomalies, each separated by distances of 6-7 normal somites. It is important to note that the cell cycle model does not assume that cells are in perfect synchrony in the PSM, but that there is some degree of cell synchrony between the cells in the PSM. This implies that a small "seeding" subpopulation of cells in each region could establish the somite pattern and the remaining cells are induced by these to give the segmentation pattern. 
The model proposes that cells destined to form somites leave Hensen's node in the strict order in which they are derived from stem cells in the node. This ensures that there is a certain amount of cell cycle synchrony among cells in the PSM, with cells lying more anteriorly in the PSM being more mature than those lying in the posterior parts. Cells remain in this strict order, so that there is some degree of cell cycle synchrony in cells destined to form a potential somite together.

Stern and co-workers conjecture the existence of two points, $P_{1}$ and $P_{2}$, in the cell cycle of mesodermal cells destined to form somites, which lie $90 \mathrm{~min}$ apart and between which cells become competent to segment. The synchrony assumption ensures that a small fraction of the cells destined to form a somite together will reach the point $P_{2}$ in their cell cycle before the others of that potential somite. Upon reaching $P_{2}$ this fraction of cells, termed pioneer cells, produce and emit a signal along the PSM. Any cell at a point in its cycle between $P_{1}$ and $P_{2}$ would respond to such a signal by increasing adhesion to neighbouring cells which are responding in a similar manner, forming a potential somite. At this point a cell has been specified as somitic, and it will become refractory to the signal. Specified cells go on to segment and form somites one cell cycle later (Fig. 1). It should be noted that the PSM is made up of two cell cycles worth of PSM cells, and that the cell cycle mechanism acts on the most anterior cell cycle.

Figure 2 contains a graphical representation of the way in which somites are proposed to form in the cell cycle model. The lower (upper) line can be thought of as representing the point $P_{1}\left(P_{2}\right)$ as it moves down the embryonic axis. The positions of the presumptive somites are found by tracing the lines as shown in the diagram, and relative somite sizes are illustrated underneath. Since the horizontal axis measures distance, and the vertical axis measures time, we can think of the slope of the lines representing $P_{1}$ and $P_{2}$ as measuring the speed with which PSM cells become competent to form somites. Note that the physical distance between the two points $P_{1}$ and $P_{2}$, caused by the cell cycle synchrony along the PSM, corresponds to the actual size of the somites formed.

Collier et al. (2000) propose a mathematical formulation of the cell cycle model, using a coupled system of non-linear partial differential equations. The two state variables which the system describes are a "somitic factor" $(u)$ which is integral in determining the fate of the cell (only cells with a high level of the factor will be specified as somitic), and a "diffusive signalling molecule" (v) produced by the pioneer cells when they reach the point $P_{2}$ in their cell cycle. The somitic factor

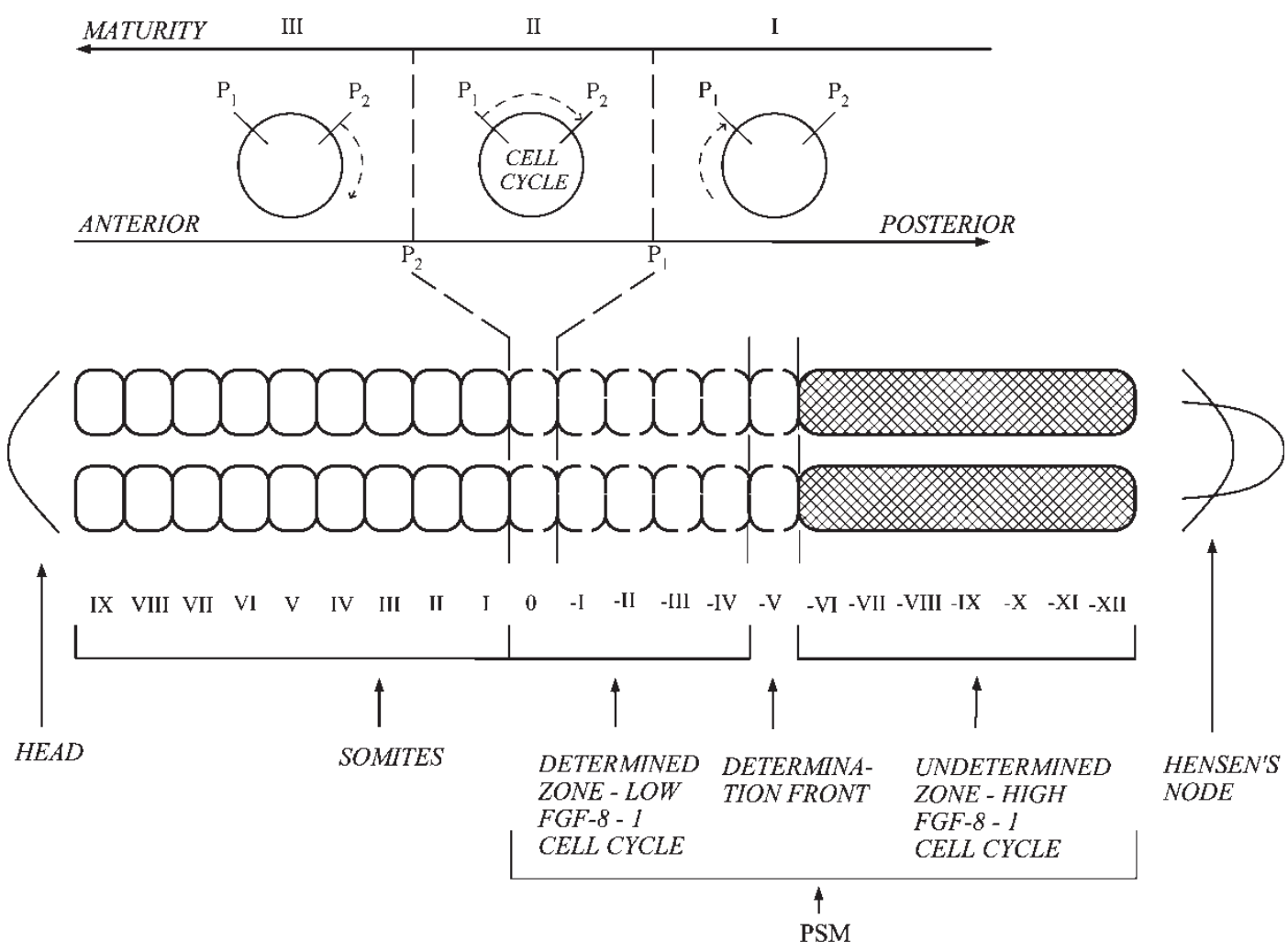

FIGURE 1 Diagrammatic representation of the vertebrate body plan during somite formation within the cell cycle model. In the top part of the diagram, the two time points $P_{1}$ and $P_{2}$ are illustrated, together with the three key stages of the cell cycle model: (I) Cells posterior to the forming somite (0) have not yet reached $P_{1}$ in their cell cycle and are not yet able to form somites. (II) Cells that are between $P_{1}$ and $P_{2}$ in their cell cycle are able to respond to the signalling molecule secreted by pioneer cells as they reach $P_{2}$ in their cycle, and hence to undergo the adhesive and migratory changes that enable them to form somites. (III) Cells anterior to the forming somite $(0)$, which have already reached the point $P_{2}$ in their cycle, have been specified as somitic. The bottom part of the diagram illustrates the position of the determination front in the PSM: cells anterior to the determination front are fixed with respect to their segmental determination, and those posterior to it are not. Notice that the determination front acts approximately one cell cycle before segmentation actually takes place. 


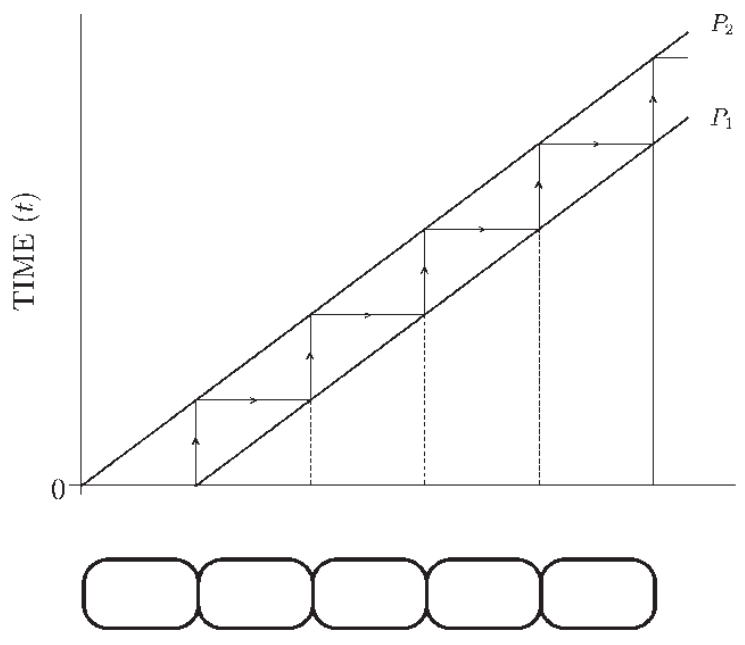

\section{DISTANCE ALONG THE CRANIAL-CAUDAL AXIS $(x)$}

FIGURE 2 Illustration of the manner in which somites are proposed to form in the cell cycle model. In the top diagram, the positions of successive somites are found by tracing the lines as shown. The bold lines indicate the positions of the points $P_{1}$ (lower) and $P_{2}$ (upper). The bottom diagram illustrates the relative somite sizes.

could be a transcription factor or a precursor to an adhesion molecule. $x$ is taken to be distance down the AP axis, with the origin fixed in a given somite, and $t$ measures time. The differential equations for this model are

$$
\begin{gathered}
\frac{\partial u}{\partial t}=\frac{(u+\mu v)^{2}}{\gamma+\rho u^{2}} \chi_{u}(x, t)-\nu u, \\
\frac{\partial v}{\partial t}=\frac{\kappa}{\epsilon+u} \chi_{v}(x, t)-\lambda v+D \frac{\partial^{2} v}{\partial x^{2}},
\end{gathered}
$$

where

$$
\begin{aligned}
& \chi_{u}(x, t)=H\left(c t-x+x_{1}\right), \\
& \chi_{v}(x, t)=H\left(c t-x+x_{2}\right),
\end{aligned}
$$

and $\mu, \gamma, \rho, \nu, \kappa, \epsilon, \lambda, D, x_{1}, x_{2}$, and $c$ are positive constants, with $x_{2}<x_{1}$ and $x_{2}-x_{1}=1$. Note that $P_{1} \leftrightarrow x_{1}+c t$ and $P_{2} \leftrightarrow x_{2}+c t$. The Heaviside function $H$ is defined to be

$$
H(y)= \begin{cases}1 & \text { if } y \geq 0 \\ 0 & \text { if } y<0\end{cases}
$$

Taking the embryonic axis to be fixed with respect to the cells, and letting Hensen's node and the PSM move down the axis at constant speed $c$, we consider the domain

$$
0 \leq x \leq d(t), \quad t \geq 0,
$$

where $d(t)$ is the position of a point that moves down the embryonic axis with constant velocity $c$.

In this mathematical model it is important to ensure that coordinated segmentation occurs. Collier et al.
(2000) consider the corresponding phase plane (by setting $D=0$ ) in three distinct regions - cells posterior to $P_{1}$, cells between $P_{1}$ and $P_{2}$, and cells anterior to $P_{2}$ - to derive sufficient parameter bounds to ensure that all cells destined to form a potential somite together adhere at the same time. Subject to these constraints, numerical simulations of the model equations produce results predicted by the cell cycle model, showing that robust pattern generation can occur. Emission of a signal from pioneer cells reaching $P_{2}$ results in a synchronous rise in level of the somitic factor in cells situated between $P_{1}$ and $P_{2}$ and hence in coordinated segmentation of somites. As shown in Fig. 3 , the signalling molecule travels down the axis as a series of pulses of $v$, approximately 20 time units apart, with the first peak occurring at $x=0$ and with each subsequent peak displaced one spatial unit more caudally than its predecessor. The somitic factor wavefront appears to move down the cranio-caudal axis as a series of jumps as successive groups of cells are triggered to become somitic: the peak at $x=0$

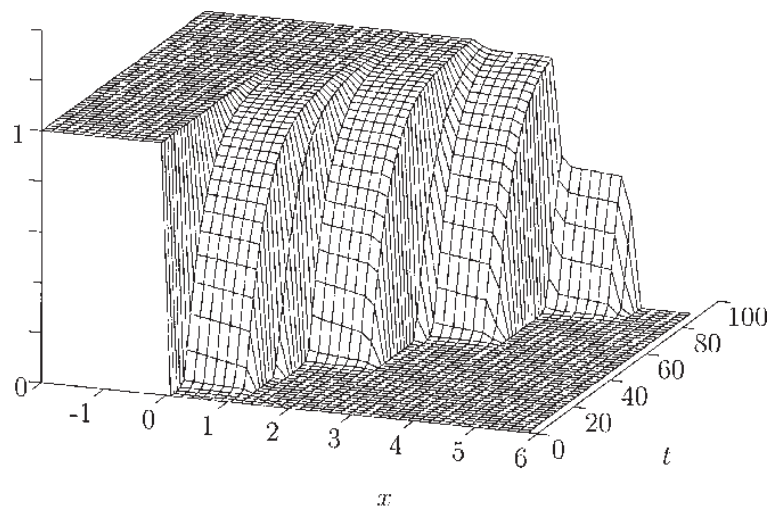

A Jumps in $u(x, l)$

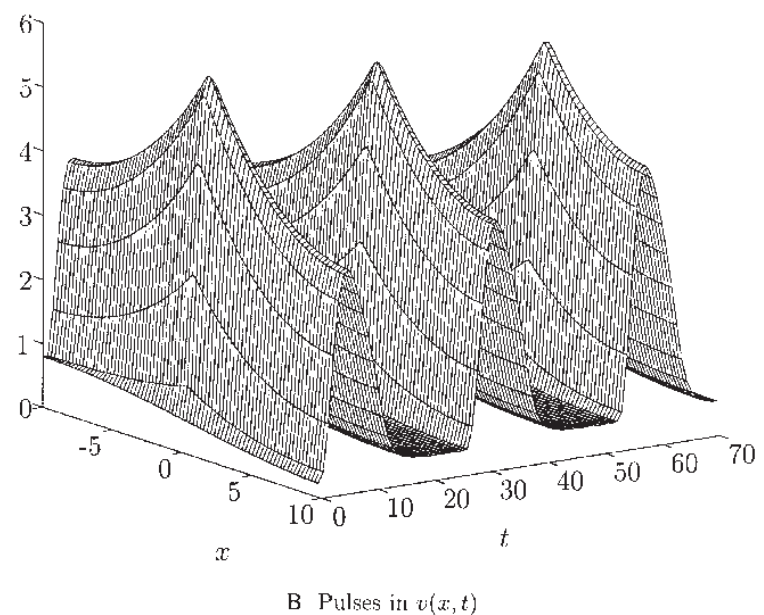

FIGURE 3 Numerical solution for the signalling model showing the spatio-temporal dynamics of the somitic factor (above) and the signalling molecule (below). Each peak in $v$ corresponds to a signal being emitted by a group of pioneer cells reaching $P_{2}$ in their cell cycle. The signal diffuses quickly along the embryonic axis, and there is a rapid rise in the somitic factor $u$ which results in somite specification. Parameters are $\mu=5 \times 10^{-4}, c=5 \times 10^{-2}, \kappa=8, \epsilon=10^{-3}, D=80, \gamma=2 \times 10^{-2}$. 
corresponds to a fairly rapid jump in $u$ occurring in all cells situated between $x=0$ and 1 , etc.

Criticisms have been made of the cell cycle model. Palmeirim et al. (1997) have argued against the role of the cell cycle as a segmentation clock based on the cycling times of $c$-hairy- 1 in the PSM. The expression of this gene occurs with a periodicity similar to the time it takes to form a single somite $(\approx 90 \mathrm{~min})$ rather than the observed cell cycle length $(\approx 9 \mathrm{~h})$. However, we do not yet know whether the major role of this gene is in the allocation of cells to individual somites or rather in the subdivision of somites into anterior and posterior compartments (Collier et al., 2000). If the latter is true, then somite and somitic boundary formation may be controlled by one or two segmentation clocks. To date, there is no direct link between the cell cycle and $c$-hairy- 1 oscillations. Nevertheless, there is evidence suggesting that both are regulated by the same type of post-transcriptional modification and therefore could be part of the same clock (Schnell et al., 2002).

Roy et al. (1999) have also suggested that a re-evaluation of the cell cycle as a "segmentation clock" must be made after finding that in zebrafish embryos heat shock anomalies occur in periodic units that do not match the cell cycle duration. However, it is worth noting that the heat shock anomalies appear at exactly twice the frequency predicted by the cell cycle model. One possible scenario is that two separate genes or two separate clocks linked to the cell cycle, but halfa-cycle out of phase, regulate somite formation in these species (Collier et al., 2000), because this group of teleosts has undergone an additional round of genome duplication during evolution (Richardson et al., 1997). Supporting this suggestion is the finding that a member of the hairy-enhancer of slip family, her-1, has an expression pattern in every other somite in zebrafish (Müller et al., 1996), unlike any gene thus far described in other vertebrates (del Barco Barrantes et al., 1999; Collier et al., 2000).

The cell cycle model seems to be a realistic model as it captures many of the experimental observations, and it is the only model to date that can explain the heat shock experiments. We have recently shown that the cell cycle mechanism can indeed give rise to the periodic pattern of somites observed in normal embryos (Collier et al., 2000; Schnell et al., 2002) and also to the abnormal patterns observed after heat shock. Moreover, we feel that the results on the FGF-8 treatment anomalies suggest that the cell cycle is intimately involved in the process of somitogenesis.

\section{The Role of Cell Cycle and FGF-8 in Somite Formation}

Following Dubrulle et al. (2001) and Vasiliauskas and Stern (2001), we hypothesize that there is some interaction between the level and the gradient of FGF-8 in the PSM that affects the rate at which PSM cells mature to become competent to segment. We propose that the cell cycle, acting as a segmentation clock, interacts with the FGF-8 determination front to gate cells into potential somites.

Figure 1 illustrates that the PSM can be divided up into two regions, according to FGF-8 signalling levels. The first part lies anterior to the determination front, has a low level of FGF-8 signalling and is made up of roughly one cell cycle worth of cells. Cells are committed to forming part of a somite. The second part lies posterior to the determination front, has a high level of FGF-8 signalling and is also made up roughly of one cell cycle worth of cells. Cells in this region are still immature and could adopt a number of possible fates. That the segmental program and the axial identity are specified around the level of somites $-\mathrm{IV} / \mathrm{V}$, the determination front (Dubrulle et al., 2001), suggests that this could be the site at which the level of FGF-8 concentration drops below some critical threshold to permit segmentation.

In a control embryo, a spatially varying FGF-8 concentration profile exists along the PSM: a high level of expression is present in the most caudal cells, and this level decreases in a graded fashion down to the level of the determination front. This is illustrated in Fig. 4A. The FGF-8 gradient is a mRNA gradient, highest in the node region and progressively decreasing. If we assume that the mRNA is translated at the same rate as it is synthesized, then the FGF-8 protein will also be produced following a similar profile to the mRNA and it will remain at the same relative position in the PSM throughout somitogenesis. Mathematically, this FGF-8 regulation can be modelled by assuming that Hensen's node is the source of FGF-8 in the PSM and that diffusion of the molecule along the PSM sets up the concentration profile as mentioned. This assumption would allow the incorporation of a new equation into our previous mathematical formulation (Collier et al., 2000; Schnell et al., 2002) and seems appropriate for the system since the node is regressing with the same speed at which somites are forming: founder cells in the node undergo mitosis and produce the PSM mesoderm cells at a rate which keeps the PSM of constant length, with cells moving cranially up through the PSM as they mature.

Following Dubrulle et al. (2001) we assume that for a cell at a particular point, competence to segment will only be achieved when FGF-8 signalling has decreased below a certain threshold level, this level being that expressed at the position of the determination front. The spatial profile of FGF-8 will regress along with the node, ensuring that the relative position of the determination front stays at a constant level in the PSM throughout somitogenesis as is consistent with experimental data. Hence, at any point in the PSM, the concentration of FGF-8 will decrease monotonically over time.

Ectopic expression of FGF-8 throughout the PSM would cause this spatially-varying profile to be "wiped out", and the value of FGF-8 expression to be too large everywhere to allow somite formation. This is 

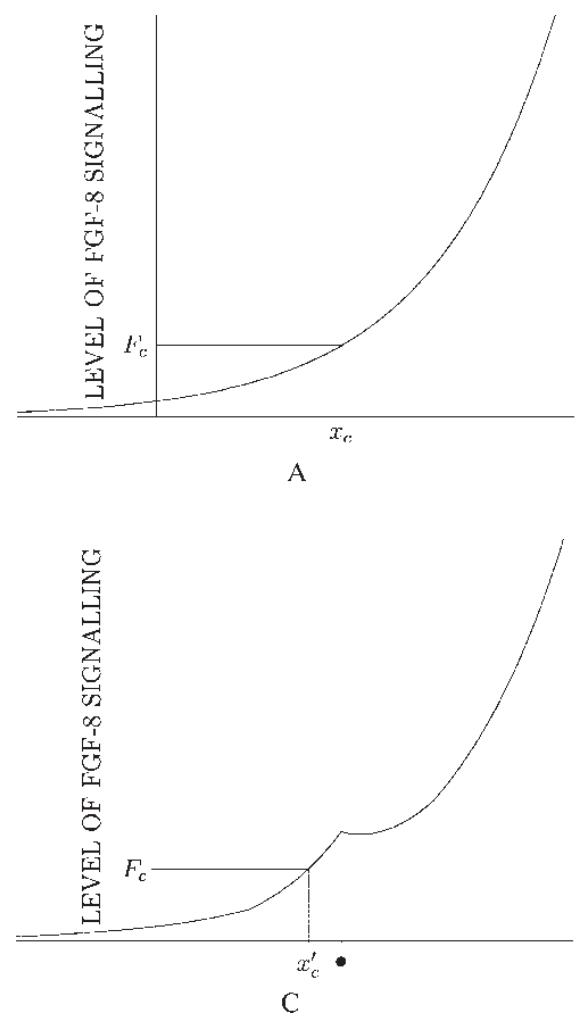
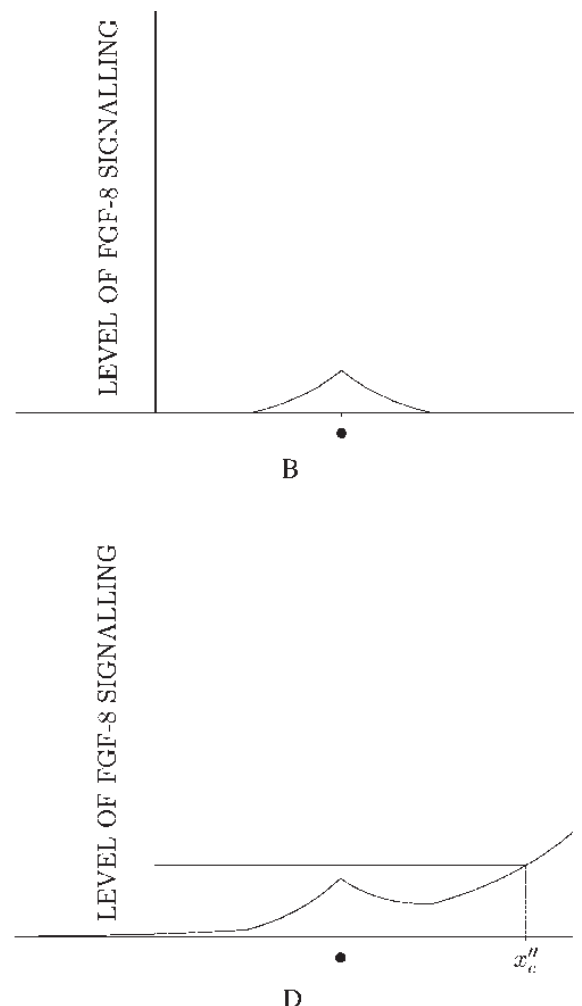

FIGURE 4 A schematic view of the way in which the level of FGF-8 signalling changes over time with local application of FGF-8 at a constant axial level $(\bullet)$ and the main source of FGF-8 moving caudally. (A) The FGF-8 signalling profile in a control embryo with the threshold concentration level of FGF-8 clearly marked $\left(F_{c}\right)$, as is the point in the PSM at which this level is reached $\left(x_{c}\right)$. (B) A profile that could be set up by a bead soaked in FGF-8. (C) The level of endogenous FGF-8 signalling with the presence of a local source of FGF-8. Note that in this case, the point at which the threshold level of FGF-8 signalling is reached $\left(x_{c}^{\prime}\right)$ is more anterior with application of FGF-8, $x_{c}^{\prime}<x_{c}$. (D) After some time, the effect of the bead is no longer relevant as the undetermined front $x_{c}^{\prime \prime}$ has moved caudally out of the range of the diffusion from the bead. In all diagrams, the horizontal axis measures distance along the AP axis and corresponds to presumptive somites at levels -VI to -XII in Fig. 1.

consistent with experimental observations in which ectopic FGF-8 expression throughout the PSM causes cells to remain unsegmented, as if they were forever young (Vasiliauskas and Stern, 2001), and our model predicts that somite formation would not occur.

Since FGF-8 signalling has no effect on the period of oscillation of the cycling genes (Dubrulle et al., 2001), we propose that it does not alter the timing of the $P_{1}-P_{2}$ window of the cell cycle acting as the segmentation clock. In this way, we propose a mechanism for segmentation in line with Vasiliauskas and Stern (2001) and Dubrulle et al. (2001) in which the clock controls when the boundaries of the somites will form and FGF-8 signalling controls where the boundaries of the somites will form. The clock will work in exactly the same way as envisaged in the cell cycle model: it will gate cells according to their developmental age. FGF-8 signalling will interact with the segmentation clock, allowing only those cells which have reached the threshold level of signalling (and hence the determination front) to be competent to segment. We will assume that a cell changes its response to FGF- 8 signalling once it has passed the determination front: essentially we will assume that a cell becomes refractory to FGF-8 signalling once it has passed this point.

\section{Effect of Local Application of FGF-8}

We can test our extended model using the experimental evidence of Dubrulle et al. (2001). Suppose that we have a bead soaked in FGF-8 implanted between the lateral mesoderm and the PSM. Then FGF-8 molecules will diffuse out from the bead along the PSM in both the anterior and posterior directions, with a symmetric distribution. We illustrate this in Fig. 4B. As the spatial profile gradient of FGF-8 regresses along with the node, the bead will stay at a constant axial level, allowing the local effects to be measured. Superimposing the bead distribution onto the endogenous concentration profile of FGF-8 gives a resulting distribution of the form of that in Fig. 4C.

Diffusion of FGF-8 from the bead, along the PSM, will affect the level of FGF-8 in cells which lie within a certain distance of the bead. Cranial to the bead, the profile will be steeper and, caudal to the bead, it will become more shallow. We now consider what effect this has on segmentation, as hypothesised in our model.

Making the FGF-8 profile steeper cranial to the bead ensures that within the time frame of the specification of one somite, the determination front will not have regressed as far as it would have done in a control embryo, and hence 
fewer cells will have become mature enough to segment, resulting in an abnormally small somite. The reverse occurs caudal to the somite: the determination front will regress further than it would have done in a control embryo, and the result will be the formation of an abnormally large somite. Put concisely, local application of FGF-8 causes the progression of the determination front to slow cranially to the bead, resulting in the anterior displacement of its position relative to the PSM, and hence the formation of smaller somites and vice versa. This was observed experimentally by Dubrulle et al. (2001).

Notice that a bead soaked in a stronger solution of FGF-8 will elicit a stronger response in the embryo. FGF-8 molecules will diffuse out and affect the profile more markedly and within a larger distance of the bead. It is possible that while the profile will become steeper cranial to the bead, it may actually slacken to the point of becoming reversed caudal to the bead. Implantation in the PSM has led to a complete absence of somite boundary formation immediately cranial to the bead, with some smaller somites forming cranially to this zone (Dubrulle et al., 2001). This may be a result of the fact that the gradient of FGF-8 has become reversed: over the time taken to form one somite, there will be no new cells reaching the determination front.

It is important to notice that our model is consistent with three very important experimental observations:

Firstly, we consider the experimental evidence of Dubrulle et al. (2001, pp. 221-222) on the effect of positioning of the bead in the PSM: "when the bead was placed mid-way between the caudal-most PSM and somite -IV, only the part of the bead that was located between the bead and somite -IV was affected...no effect was ever detected in cells which were rostral to somite -IV at the time of surgery". This supports our assumption that a cell's response to signalling changes as it passes the determination front. Cells that are cranial to the determination front at the time of implantation of the bead can never be affected by changes in the FGF-8 gradient because they have become refractory to FGF- 8 signalling. In this way, we see that the link between the pattern of anomalies seen must be dependent on both the strength of the source, and its placement within the PSM.

Secondly, we consider the maximum distance over which bead anomalies could extend cranial to the bead. Whatever the changes to the FGF- 8 gradient within the PSM due to the bead, those changes can only be manifest up to the level of the determination front, since we assumed that cells become refractory to FGF-8 signalling cranial to this point. Since the undetermined zone is equivalent to one cell cycle worth of PSM cells, our model allows for anomalies to extend only over this distance, which is equivalent to 6-7 somites (Dubrulle et al., 2001).

Thirdly, our model also predicts that with bead implantation subsequent somite formation will fall back into register with the control side of the embryo. This is because the rate at which the node is regressing is constant, there is no effect upon the $P_{1}-P_{2}$ window, acting as the segmentation clock and the effects of bead implantation are only felt within a certain radius of the bead. Note that the independence of the $P_{1}-P_{2}$ window and the gradient ensures that we can also predict anomalies forming at the same time as normal somites on the control side of the embryo (Dubrulle et al., 2001).

\section{An Algorithm for Explaining the Effects of FGF-8 Application}

We showed earlier that the slope of the lines representing $P_{1}$ and $P_{2}$ in Fig. 2 is a measure of the speed at which PSM cells become competent to form somites. Our model hypothesises that local application of FGF-8 affects the rate of maturation of PSM cells, so we can look at the effects of FGF-8 application upon somite formation by varying the slope of the lines representing $P_{1}$ and $P_{2}$ in Fig. 2: varying the speed of the node in the vicinity of an implanted bead would mimic the displacement of the determination front relative to its constant axial level in the PSM.

Suppose that in a control embryo, somites are forming normally at some rate $c$, say. That is, the slope of the lines in Fig. 2 is equal to $1 / c$. Implantation of a bead soaked in FGF-8 in the PSM would cause an alteration in the slope of the lines representing $P_{1}$ and $P_{2}$ close to the bead. Cranial to the bead, the rate at which cells become competent to form somites $(c)$ will decrease, so the slope of the lines will increase, and vice-versa caudal to the bead.

Working along the lines of Schnell et al. (2002), we propose the following algorithm to describe the effects of local application of FGF-8:

- Suppose that a bead soaked in FGF-8 is grafted between the PSM and the lateral mesoderm, at a point $x^{*}$, and that the strength of the source is such that diffusion of the molecule along the PSM causes changes in the endogenous gradient of FGF-8 over a distance $\delta_{r}$ cranial to the bead and $\delta_{c}$ caudal to the bead.

- In the interval $\left(x^{*}-\delta_{r}, x^{*}\right)$ let $c \mapsto c_{r}$ where $c_{r}<c$ represents the slower rate of maturation of cells lying immediately cranial to the bead.

- In the interval $\left(x^{*}, x^{*}+\delta_{c}\right)$ let $c \mapsto c_{c}$ where $c_{c}>c$ represents the increased rate of maturation of cells which lie immediately caudal to the bead.

If we assume that the cellular environment is similar either side of the bead, then we can assume that the effects extend for the same distance both cranial and caudal to the bead. In other words, we can assume that $\delta_{r}=\delta_{c}$.

Using these assumptions, we can picture the effects of local FGF-8 application using diagrams similar to those in Fig. 2. We have two main and distinct cases: when application of FGF-8 induces the formation of an extra somite, and when it does not. Figure 5A shows the effects of moderate FGF-8 application: no extra somite is 


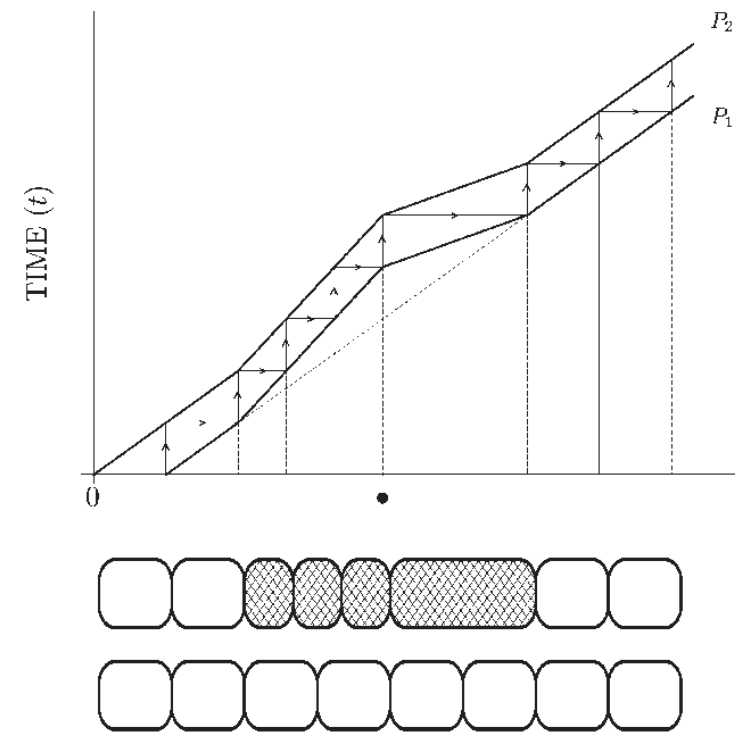

DISTANCL ALONG THE CRAAIAL-CAUDAL AXIS $(x)$

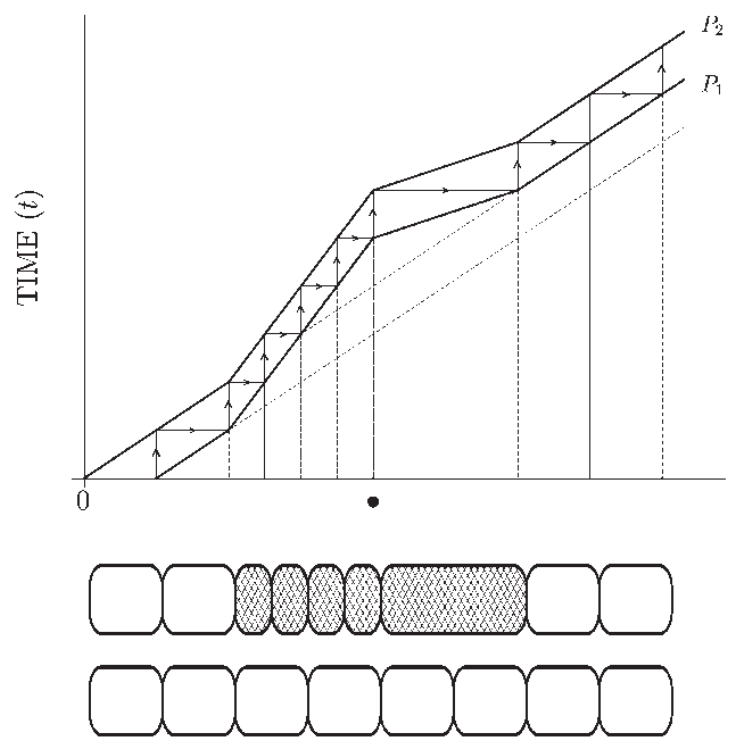

DISTANCE ALONG THE CRANIAL-CAUDAL AXIS $(x)$

A

B

FIGURE 5 An illustration of the manner in which somites are formed with local application of FGF-8. Implantation of an FGF-8 soaked bead in the PSM causes changes in the endogenous spatial profile of FGF-8 within a certain range of the bead, resulting in a series of abnormally small somites, followed by an abnormally large somite. In both subfigures, the top diagram illustrates the change in maturation rate caused by application of FGF-8, the middle diagram illustrates the somite anomalies produced and the bottom diagram shows a comparison with a control embryo. The position of the bead implantation is shown by $\bullet$ and the diagonal broken lines show the positions of $P_{1}$ and $P_{2}$ without application of FGF-8. (A) Local application does not lead to the formation of an extra somite. (B) Increasing the strength of the bead source generates a strong enough effect to produce an extra somite. Notice that here, $P_{1}$ and $P_{2}$ do not return in line with their original position.

induced. Figure 5B shows the effects of a stronger source of FGF-8: a steeper profile caused by the increase in source strength results in the formation of an extra somite. Common to both figures is the constant rate of somite formation, one per $P_{1}-P_{2}$ window or expression of cycling genes. Note that in Fig. 5B, $P_{1}$ and $P_{2}$ do not return in line with their original position, rather they are displaced one unit temporally.

These diagrams clearly show the incorporation of certain cells into differently numbered somites than their control counterparts. It can be seen that such cells will go on to segment within a different time step and will therefore experience a different number of clock oscillations before segmenting. Dubrulle et al. (2001, p. 220) demonstrate that "FGF-8 treatment can increase the number of clock oscillations experienced by PSM cells without altering their absolute axial position in tissue. Cells which experience an extra oscillation become incorporated into a differently numbered somite and exhibit Hox expression indicative of a more posterior fate when compared with contralateral control cells". Our model clearly accounts for this result.

Earlier in this article, we detailed experimental evidence provided by Dubrulle et al. (2001) showing that with or without the formation of an extra somite through FGF-8 application, subsequent somites caudal to the bead fall back into register with their lateral control neighbours. Our results suggest when formation of an extra somite occurs, this realignment is achieved spatially, but with somites on the affected side forming a time step (1/c) later than those of their lateral control counterparts.

\section{Differences Between FGF-8 and Heat Shock Treatment}

Following on from the algorithm presented by Schnell et al. (2002) to describe the effects of heat shock on chick embryos, we have presented a similar algorithm to account for the anomalies produced by local application of FGF-8. Although at first glance the anomalies seen with these experimental procedures may seem qualitatively similar, the manner in which these effects are produced is hugely different.

Application of heat shock to chick embryos blocks cells at a certain stage of their cell cycle, for the duration of the shock. This produces repeated anomalies as the shock acts on all cells in the PSM and node. Local application of FGF-8, on the other hand, has no effect on the rate at which cells are progressing through their cycle. What it does affect is the number of cells which are "mature" enough to segment. Anomalies remain local to the bead, as it remains at a fixed position in the PSM, and at any one time there are only two cell cycles worth of cells in the PSM. Figure 6 shows a comparison between the manner in which anomalies are produced with heat shock and local application of FGF-8. 


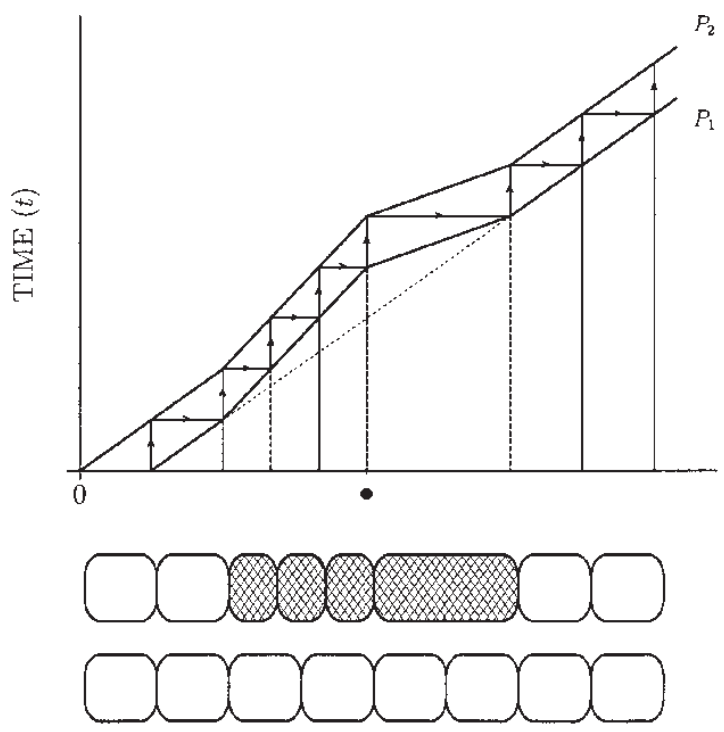

DISTANCE ALONG THE CRANIO-CALDAL AXIS $(x)$

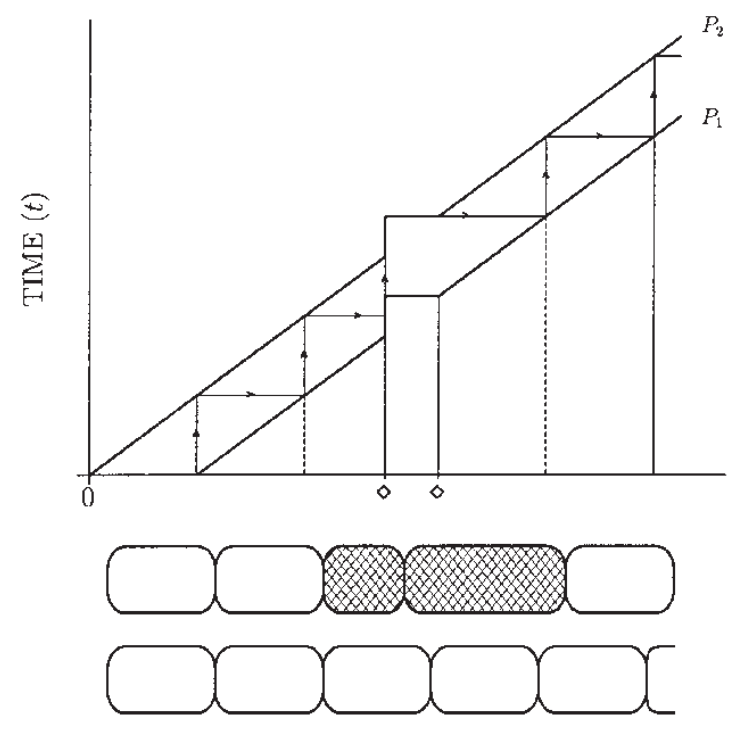

DISTANCE ALONG THE CRANIO-CAUDAL AXIS $(x)$

A

B

FIGURE 6 A comparison of the manner in which FGF-8 application and heat shock affect somite formation. (A) Local application of FGF-8 does not lead to the formation of an extra somite. The position of the bead implantation is shown by $\bullet$ and the diagonal broken lines show the positions of $P_{1}$ and $P_{2}$ without application of FGF-8. Considering the slope of the lines representing $P_{1}$ and $P_{2}$ as measuring the rate at which cells become mature to segment, we see that FGF-8 application can modify the rate of maturation within a certain radius of the bead. (B) An illustration of the manner in which somites are formed when transient heat shock is applied to chick embryos as envisaged by the cell cycle model. Applying the algorithm in Schnell et al. (2002) formation of an abnormally small somite is followed by an abnormally large somite. Heat shock affects cells between the $\diamond$ markers. Notice the diagram demonstrates heat shock blocking the cell cycle since for the duration of the shock, $P_{1}$ and $P_{2}$ remain at constant axial positions, and that future somite formation will not fall back in line with a control embryo.

\section{CONCLUSIONS}

There are a number of models in the literature for somitogenesis and these have been used to interpret the results observed recently concerning the travelling waves of c-hairy-l and l-fng in the PSM. Recent results of Vasiliauskas and Stern (2001) and Dubrulle et al. (2001) on FGF-8 have meant that a number of experimentalists have modified one of these models to be consistent with the new results while ignoring others. In this article, we have aimed to show that, in fact, these new results are inconsistent with the particular model being favoured by experimentalists, but link in nicely with the cell cycle model, which previous authors have overlooked.

We have extended the cell cycle model to account for the expression of FGF-8. The model is based on three assumptions:

i. Hensen's node can be considered mathematically as the source of FGF-8 in the PSM.

ii. Cells become refractory to the effects of FGF-8 signalling once they reach the determination zone.

iii. The cell cycle acts as a segmentation clock due to the assumption of a $P_{1}-P_{2}$ window which causes the commitment of a cell to segment in the determined zone.

The first assumption seems realistic since the node is regressing at the same speed at which somites are forming: founder cells in the node undergo mitosis and produce the PSM mesoderm cells at a rate which keeps the PSM of constant length. This ensures that the FGF-8 threshold will remain in the same relative position in the PSM throughout somitogenesis. The second assumption is suggested by Dubrulle et al. (2001) and is consistent with the experimental observation that no effect on somite formation is ever produced anterior to the determination front at the time of FGF-8 application or inhibition.

We built on the cell cycle model postulated by Stern and co-workers (Stern et al., 1988; Primmett et al., 1989) by noting that the undetermined and determined zones of the PSM are each roughly made up of one cell cycle worth of cells. Since the determination front acts one cell cycle before segmentation actually takes place, we considered $c$, the rate at which the node regresses, as able to control the rate of maturation of cells in the PSM. We were able to successfully predict all the anomalies produced by local application and inhibition of FGF-8 and demonstrate them graphically in a clear manner.

The schematic diagrams we present in Fig. 5 clearly show that with local application of FGF-8, certain presomitic cells will experience an extra oscillation of the "clock" before becoming committed to segment. This can explain the caudal shift in axial identity observed by Dubrulle et al. (2001). Figure 5B demonstrates that there are circumstances in which local application of FGF-8 is strong enough to induce the formation of an extra somite. Although further somite formation will fall back into 
register spatially with the control side of the embryo, our model suggests that these regular somites will not fall back into register temporally. It predicts that somites on the operated side will form behind their lateral control counterparts with a time lag equal to the time taken to form one somite. It would be interesting to see if this could be proved experimentally.

In future work, we will present a mathematical formulation of the new model based on the results of Collier et al. (2000) and Schnell et al. (2002), along with its analysis, and numerical simulations of the algorithm presented in this article. To incorporate more experimental evidence into the model, we need to understand the mechanisms surrounding regional specification of somites: in particular, the role of Hox genes, and how they determine the morphology of individual vertebrae (Burke et al., 1995). As mentioned previously, Zákány et al. (2001) suggest that there is a link between somite formation and the molecular clock controlling somite formation, which would maintain in phase the production of new segments with their morphological specification. Dubrulle et al. (2001) suggest that the embryo is able to count the number of somites to control when to set the boundaries of Hox gene expression. To our knowledge, the only model that addresses the regional differences of somites is Meinhardt's reaction-diffusion type model. However, it is intriguing to note that the 5-7 somite interval, which corresponds to the duration of the cell cycle, correlates with the length of somite derivatives sharing the same regional identity at an axial level (Schnell et al., 2002). In other words, each level of the vertebrate axis: occipital, cervical, thoracic, lumbar, and sacral, is usually comprised of a multiple of 5-7 vertebrae, the multiple being specific to each region (Primmett et al., 1989; Schnell et al., 2002). This links the regional specification mechanism with the cell cycle and hence our model.

\section{Consistency with Other Models for Somite Formation}

We have shown that an extension of the cell cycle model can explain the effects of FGF-8 during somitogenesis. However, we are not proposing the cell cycle model as the ultimate explanation for somite formation. As we have previously mentioned, models are partial representations of reality and cannot account for all experimental observations. In fact, we propose that, with suitable modification, a number of models can be viewed as consistent with the observations and so it is, we feel, a mistake to consider only one model, which seems presently to be the case.

Vasiliauskas and Stern (2001) highlight the possibility suggested by Slack (1991) that it could be the slope of the FGF-8 profile that is important in determining the progression of the wavefront in Cooke and Zeeman's model. Local application of FGF-8 by implantation of a bead "could result in a continuous cranial shift of the wavefront ... accounting for the continuous production of smaller somites followed by a larger somite". Used in this sense, it seems that the clock and wavefront model could still be consistent with the effects of local application of FGF-8.

Although, in its present form, the reaction-diffusion model does not explain the effects of local FGF-8 application, it is possible that it could be extended to do so using FGF-8 as the positional information gradient required by Meinhardt's model (Meinhardt, 1986; Dale and Pourquie, 2000). A link with the cell cycle would be required to predict that the maximum distances over which anomalies could extend over is equal to one cell cycle worth of PSM cells.

Therefore, it seems that we have a group of models describing the process of somite formation: the clock and wavefront model in its various forms, the reactiondiffusion model, and the cell cycle model. Assuming that the $P_{1}-P_{2}$ time window in the cell cycle is acting as the segmentation clock, each of the models reviewed in this article could be consistent with the others at some underlying level and each can explain various experimental findings. In order to distinguish between the models described above, it will be necessary to look more closely at the underlying biology.

Further studies on these models will help us to understand the developmental mechanisms in vertebral patterning and to identify protective factors for normal spinal developmental, and ultimately will create a better understanding of ways to prevent and treat vertebral malformations.

\section{Acknowledgements}

REB would like to thank EPSRC for a studentship in Mathematics, and Wadham College (Oxford) for a Wadham College Senior Scholarship. SS acknowledges support from the José Gregorio Hernández Award (Academia Nacional de Medicina, Venezuela; Pembroke College, Oxford), ORS Award (Committee of ViceChancellors and Principals of the Universities the United Kingdom), Programa de Cofinanciamiento Institucional IVIC-CONICIT (CONICIT, Venezuela), Lord Miles Senior Scholarship in Science (Pembroke College) and the Research Training Fellowship Programme in Mathematical Biology (Grant No. 069155) of the Wellcome Trust (London). PKM was supported by a Royal Society/Leverhulme Trust Senior Research Fellowship for part of this work. Part of this document has been typed with the aid of peditPro provided by the courtesy of PaulComputing (http://www. paulcomputing.com).

\section{References}

del Barco Barrantes, I., Elia, A.J., Wünsch, K., Hrabě de Angelis, M., Mak, T.W., Rossant, J., Conlon, R.A., Gossler, A. and de la Pompa, J.L. (1999) "Interaction between Notch signalling and Lunatic fringe during somite boundary formation in the mouse", Curr. Biol. 9, 470-480. 
Bulman, M.P., Kusumi, K., Frayling, T.M., McKeown, C., Garrett, C., Lander, E.S., Krumlauf, R., Hattersley, A.T., Ellard, S. and Turnpenny, P.D. (2000) "Mutations in the human Delta homologue, DLL3, cause axial skeletal defects in spondylocostal dysostosis", Nature Genet. 24, 438-441.

Burke, A.C., Nelson, C.E., Morgan, B.A. and Tabin, C. (1995) "Hox genes and the evolution of vertebrate axial morphology", Development 121, 333-346.

Collier, J.R., McInerney, D., Schnell, S., Maini, P.K., Gavaghan, D.J., Houston, P. and Stern, C.D. (2000) "A cell cycle model for somitogenesis: mathematical formulation and numerical simulations", J. Theor. Biol. 207, 305-316.

Cooke, J. (1975) "Control of somite number during morphogenesis of a vertebrate, Xenopus laevis", Nature 254, 196-199.

Cooke, J. (1998) "A gene that resuscitates a theory: somitogenesis and a molecular oscillator", Trends Genet. 14, 85-88.

Cooke, J. and Zeeman, E.C. (1976) "A clock and wavefront model for control of the number of repeated structures during animal morphogenesis", J. Theor. Biol. 58, 455-476.

Dale, K.J. and Pourquie, O. (2000) "A clock-work somite", Bioessays 22, $72-83$.

Dubrulle, J., McGrew, M.J. and Pourquié, O. (2001) "FGF signaling controls somite boundary position and regulates segmentation clock control of spatiotemporal Hox gene activation", Cell 106, 219-232.

Erol, B., Kusumi, K., Lou, J. and Dormans, J.P. (2002) "Etiology of congenital scoliosis", Univ. Penn. Orthop. J. 15, 37-42.

Evrard, Y.A., Lun, Y., Aulehla, A., Gan, L. and Johnson, R.L. (1998) "lunatic fringe is an essential mediator of somite segmentation and patterning", Nature 394, 377-381.

Gossler, A. and Hrabě de Angelis, M. (1998) "Somitogenesis", Curr. Top. Dev. Biol. 38, 225-287.

Ingalls, T.H. and Curley, F.J. (1957) "Principles governing the genesis of congetical malformations induced in mice by hypoxia", $N$. Engl. J. Med. 257, 1121-1127.

Jiang, Y.J., Aerne, B.L., Smithers, L., Haddon, C., Ish-Horowicz, D. and Lewis, J. (2000) "Notch signalling and the synchronization of the somite segmentation clock", Nature 408, 475-479.

Li, L.H., Krantz, I.D., Deng, Y., Genin, A., Banta, A.B., Collins, C.C., Qi, M., Trask, B.J., Kuo, W.L., Cochran, J., Costa, T., Pierpont, M.E.M., Rand, E.B., Piccoli, D.A., Hood, L. and Spinner, N.B. (1997) "Alagille syndrome is caused by mutations in human Jagged1, which encodes a ligand for Notch1", Nature Genet. 16, 243-251.

Loder, R.T., Hernandez, M.J., Lerner, A.L., Winebrener, D.J., Goldstein, S.A., Hensinger, R.N., Liu, C.Y. and Schork, M.A. (2000) "The induction of congenital spinal deformities in mice by maternal carbon monoxide exposure", J. Pediatr. Orthop. 20, 662-666.

McGrew, M.J., Dale, J.K., Fraboulet, S. and Pourquié, O. (1998) "The lunatic fringe gene is a target of the molecular clock linked to somite segmentation in avian embryos", Curr. Biol. 8, 979-982.

Meinhardt, H. (1982) Models of Biological Pattern Formation (Academic Press, London).

Meinhardt, H. (1986) "Models of segmentation", In: Bellairs, R., Ede, D.A. and Lash, J.W., eds, Somites in Developing Embryos (Plenum Press, New York), pp 179-189.

Müller, M., von Weizsäcker, E. and Campos-Ortega, J.A. (1996) "Expression domains of a zebrafish homologue of the Drosophila pair-rule gene hairy correspond to primordia of alternating somites", Development 122, 2071-2078.

Murakami, U. and Kameyama, Y. (1963) "Vertebral malformations in the mouse fetus caused by maternal hypoxia during early stages of pregnancy", J. Embryol. Exp. Morphol. 11, 107-118.

Murray, F.J., Schwetz, B.A., Crawford, A.A., Henck, J.W., Quast, J.F. and Staples, R.E. (1979) "Embryotoxicity of inhaled sulfur dioxide and carbon monoxide in mice and rabbits", J. Environ. Sci. Health 13, $233-250$.

Oda, T., Elkahloun, A.G., Pike, B.L., Okajima, K., Krantz, I.D., Genin, A., Piccoli, D.A., Meltzer, P.S., Spinner, N.B., Collins, F.S. and Chandrasekharappa, S.C. (1997) "Mutations in the human Jagged-1 gene are responsible for Alagille syndrome", Nature Genet. 16, $235-242$.

Palmeirim, I., Henrique, D., Ish-Horowicz, D. and Pourquié, O. (1997) "Avian hairy gene expression identifies a molecular clock linked to vertebrate segmentation and somitogenesis", Cell 91, 639-648.
Pourquié, O. and Kusumi, K. (2001) "When body segmentation goes wrong", Clin. Genet. 60, 409-416.

Primmett, D.R.N., Stern, C.D. and Keynes, R.J. (1988) "Heat shock causes repeated segmental anomalies in the chick embryo", Development 104, 331-339.

Primmett, D.R.N., Norris, W.E., Carlson, G.J., Keynes, R.J. and Stern, C.D. (1989) "Periodic segmental anomalies induced by heat shock in the chick embryo are associated with the cell cycle", Development 105, 119-130.

Richardson, M.K., Hanken, J., Gooneratne, M.L., Pieau, C., Raynaud, A., Selwood, L. and Wright, G.M. (1997) "There is no highly conserved embryonic stage in the vertebrates: implications for current theories of evolution and development", Anat. Embryol. (Berl.) 196, 91-106.

Rivard, C.H. (1986) "Effects of hypoxia on the embryogenesis of congenital vertebral malformations in the mouse", Clin. Orthop. 208, $126-130$.

Rivard, C.H., Narbaitz, R. and Uhthoff, H.K. (1979) "Time of induction of congenital vertebral malformations in human and mouse embryo", Orthop. Rev. 8, 135-139.

Roy, M.N., Prince, V.E. and Ho, R.K. (1999) "Heat shock produces periodic somitic disturbances in the zebrafish embryo", Mech. Dev. 85, 27-34.

Saga, Y. and Takeda, H. (2001) "The making of the somite: molecular events in vertebrate segmentation", Nat. Rev. Genet. 2, 835-845.

Sawada, A., Shinya, M., Jiang, Y.J., Kawakami, A., Kuroiwa, A. and Takeda, H. (2001) "Fgf/MAPK signalling is a crucial positional cue in somite boundary formation", Development 128, 4873-4880.

Schnell, S. and Maini, P.K. (2000) "Clock and induction model for somitogenesis", Dev. Dyn. 217, 415-420.

Schnell, S., Painter, K.J., Maini, P.K. and Othmer, H.G. (2000) "Spatiotemporal pattern formation in early development: a review of primitive streak formation and somitogenesis", In: Maini, P.K., and Othmer, H.G., eds, Mathematical Models for Biological Pattern Formation (Springer, New York), pp 11-37.

Schnell, S., Maini, P.K., McInerney, D., Gavaghan, D.J. and Houston, P. (2002) "Models for pattern formation in somitogenesis: a marriage of cellular and molecular biology", C.R. Biol. 325, $179-189$.

Schwetz, B.A., Smith, F.A., Leong, B.K. and Staples, R.E. (1979) "Teratogenic potential of inhaled carbon monoxide in mice and rabbits", Teratology 19, 385-392.

Singh, J., Aggison, L. and Moore-Cheatum, L. (1993) "Teratogenicity and developmental toxicity of carbon-monoxide in protein-deficient mice", Teratology 48, 149-159.

Slack, J.M.W. (1991) From Egg to Embryo: Regional Specification in Early Development, 2nd Ed. (Cambridge University Press, Cambridge).

Stern, C.D. and Bellairs, R. (1984) "Mitotic activity during somite segmentation in the early chick embryo", Anat. Embryol. (Berl.) 169, 97-102.

Stern, C.D., Fraser, S.E., Keynes, R.J. and Primmett, D.R.N. (1988) "A cell lineage analysis of segmentation in the chick embryo", Development 104S, 231-244.

Stickney, H.L., Barresi, M.J.F. and Devoto, S.H. (2000) "Somite development in zebrafish", Dev. Dyn. 219, 287-303.

Stockdale, F.E., Nikovits, Jr., W. and Christ, B. (2000) "Molecular and cellular biology of avian somite development", Dev. Dyn. 219, 304-321.

Vasiliauskas, D. and Stern, C.D. (2001) "Patterning the embryonic axis: FGF signaling and how the vertebrate embryos measure time", Cell 106, 133-136.

Veini, M. and Bellairs, R. (1986) "Heat shock effects in chick embryos", In: Bellairs, R., Ede, D.A. and Lash, J.W., eds, Somites in Developing Embryos (Plenum Press, New York), pp 135-145.

Zákány, J., Kmita, M., Alarcon, P., de la Pompa, J.-L. and Duboule, D. (2001) "Localized and transient transcription of Hox genes suggests a link between patterning and the segmentation clock", Cell 106, 207-217.

Zeeman, E.C. (1974) "Primary and secondary waves in developmental biology", Some Mathematical Questions in Biology, VI (Proc. Eighth Sympos., Mathematical Biology, San Francisco, Calif., 1974, Lectures on Math. in the Life Sciences, Vol. 7, Amer. Math. Soc., Providence, R.I., pp 69-161.

Zhang, N. and Gridley, T. (1998) "Defect in somite formation in lunatic fringe-deficient mice", Nature 394, 374-377. 


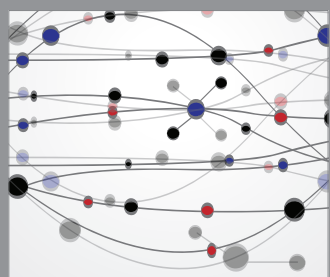

The Scientific World Journal
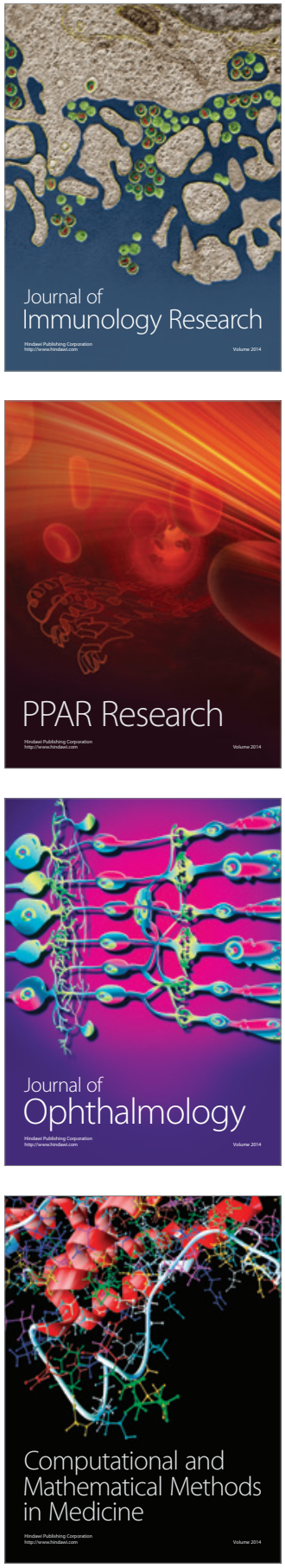

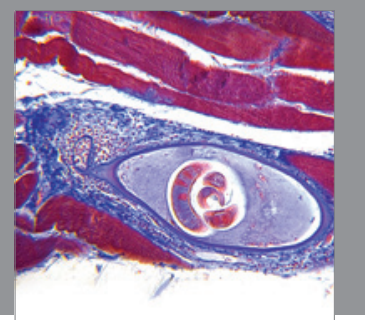

Gastroenterology

Research and Practice
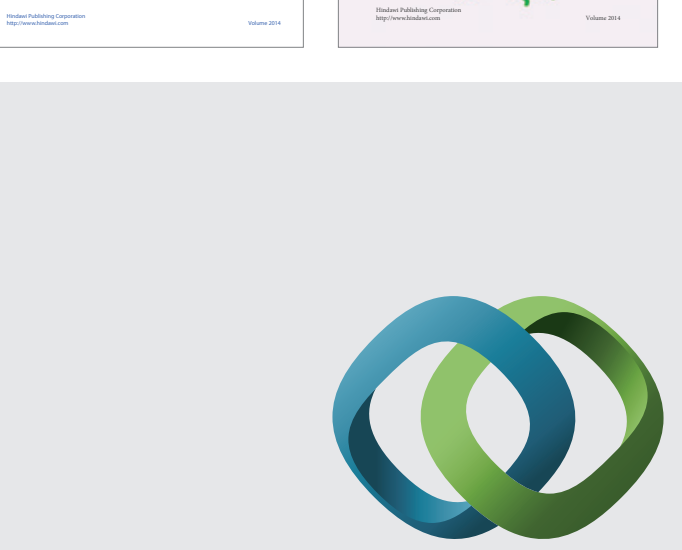

\section{Hindawi}

Submit your manuscripts at

http://www.hindawi.com
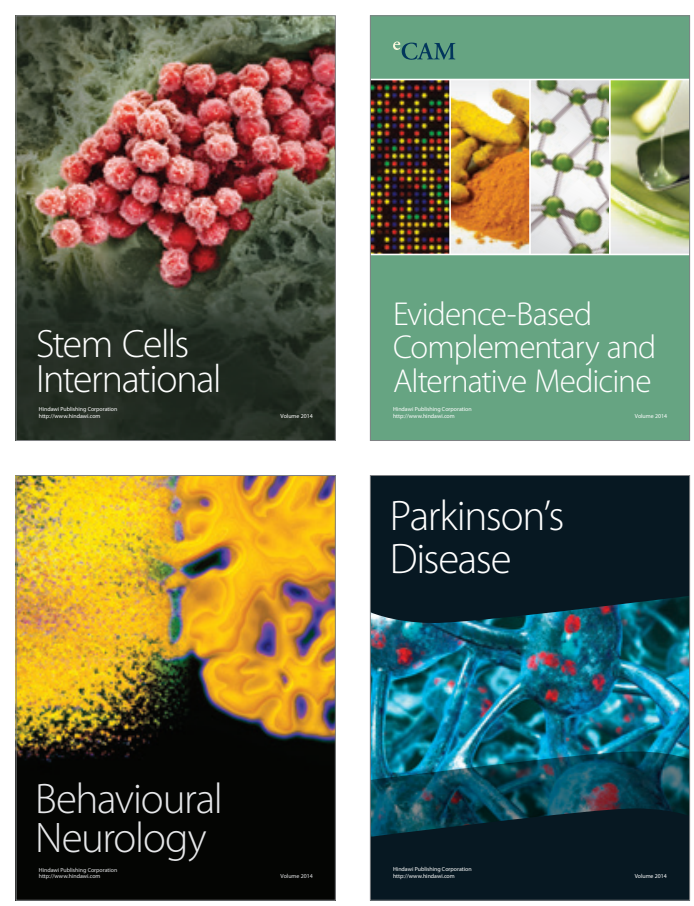

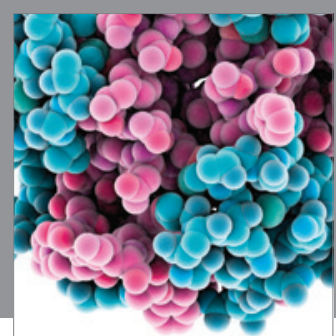

Journal of
Diabetes Research

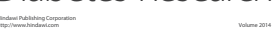

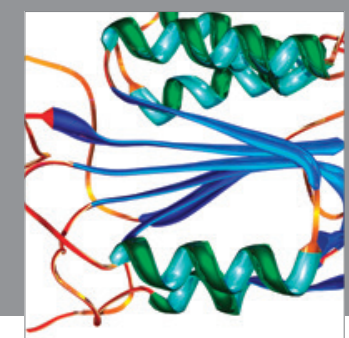

Disease Markers
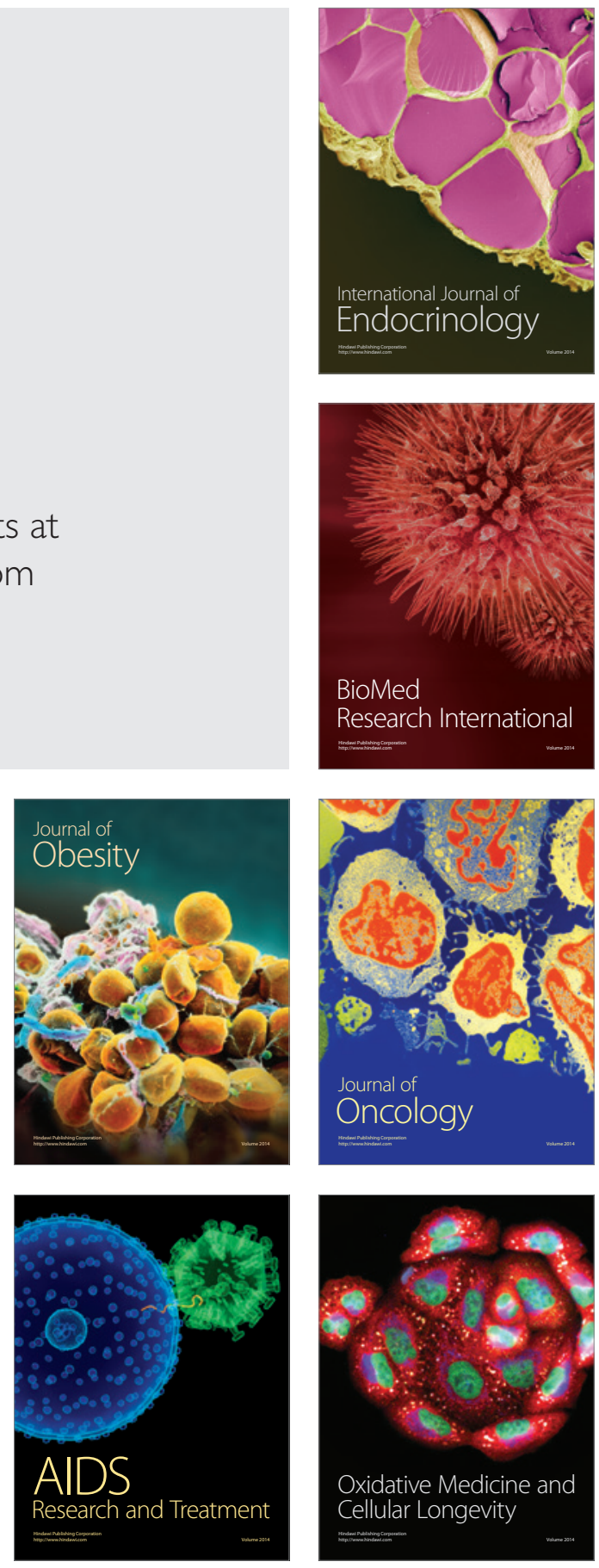